\title{
Chondrosarcoma of the Proximal Phalanx of the Fourth Digit: A Rare Location
}

\author{
Thivi Vasilakaki $^{\mathrm{a}}$ Aikaterini Tsavari $^{\mathrm{a}}$ Evangelia Skafida $^{\mathrm{a}}$ \\ Kalliroi Koulia ${ }^{a}$ Despina Myoteri ${ }^{a}$ \\ Xanthipi Grammatoglou ${ }^{a} \quad$ Alexandra Zisi $^{b}$ \\ Nikolaos Firfiris ${ }^{c}$ Kassiani Manoloudaki ${ }^{\mathrm{a}}$ \\ a'Department of Pathology, 'Tzaneion' General Hospital of Piraeus, Piraeus, \\ 'Department of Chemistry, University of Athens 'Kapodistriako', Athens, and \\ 'Department of Anesthesiology, General Hospital of Larissa, Larissa, Greece
}

\section{Key Words}

Chondrosarcomas . Small bones of the hands and feet - Secondary chondrosarcoma of the small bones

\begin{abstract}
Introduction: Cartilaginous tumors involving the small bones of the hands and feet are usually benign such as enchondroma, chondromyxoid fibroma and chondroblastoma. The small bones of the hands and feet are rarely involved by primary chondrosarcoma. Proximal phalanges are the most common sites in the hands, but the fourth digit is the least common site.

Case Presentation: We report a case of a 76-year-old Greek female who presented to our hospital with a painful swollen mass measuring $4.5 \times 2.6 \mathrm{~cm}$ on the fourth digit of the left hand. The radiograph showed a destructive, permeative lytic tumor of the proximal phalanx with extension into soft tissue. The patient underwent curettage, and the microscopic examination of the specimen revealed grade 2 chondrosarcoma.

Conclusion: Cartilaginous tumors involving the small bones of the hands and feet are usually benign such as enchondroma, chondromyxoid fibroma and chondroblastoma. Primary chondrosarcoma is the third most common malignancy of bone after myeloma and osteosarcoma, but the small bones of the hands and feet are very rarely involved by chondrosarcoma ( $1 \%$ of all chondrosarcoma). However, in these cases differentiation between a benign lesion and chondrosarcoma may be difficult. Occasionally chondrosarcoma of the hands and feet is associated with multiple recurrences or distal metastasis.
\end{abstract}




\section{Case Presentation}

A 76-year-old Greek female presented to our hospital with a painful swollen mass measuring $4.5 \times$ $2.6 \mathrm{~cm}$ on the fourth digit of the left hand. The symptoms were of long duration (several months).The radiograph showed a destructive, permeative lytic tumor of the proximal phalanx with extension into soft tissue. Linear areas of calcium deposit were present in the tumor. The soft tissue mass was relatively well marginated (fig. 1). Procedures such as chest radiography and abdominal ultrasonography to look for metastases produced negative results. The treatment was curettage of the lesion, and the microscopic examination of the specimen revealed grade 2 chondrosarcoma (fig. 2 , fig. 3). Two years later, the patient showed no evidence of recurrence or metastasis.

\section{Discussion}

Primary chondrosarcoma is a tumor of adulthood and old age. The majority of patients are older than 50 years. Patients with secondary chondrosarcoma are somewhat younger, with approximately $52 \%$ being in the third and fourth decades of life [1-3]. Cartilaginous tumors involving the small bones of the hands and feet are usually benign such as enchondroma, chondromyxoid fibroma and chondroblastoma [ 1 , 4]. Although chondrosarcoma is rare in these locations, the difficulty in differentiating enchondroma from well-differentiating chondrosarcoma is well recognized $[1,2,5]$. The distinction between them depends so much on the radiographic finding that a pure histological interpretation is hazardous [2]. Essential to differentiation from enchondroma may be cortical destruction, soft tissue mass and permeative pattern $[1,2]$.

Regarding the location of chondrosarcoma, proximal phalanges are the most common sites in the hands. The fifth digit has the highest incidence of chondrosarcoma and the fourth digit is the least common site in the hands. When distal phalanges of the hands are involved, the thumb is the most common site. The calcaneus is the most common site in the feet $[1,3,6-8]$. Secondary chondrosarcoma constitutes about $11 \%$ of all chondrosarcomas in small bones of the hands and feet $[1,3,9,10]$.

The treatment of chondrosarcoma is surgical excision with curettage, resection or amputation. Curettage of the lesion leads to a very high rate of recurrence. Chondrosarcoma is associated with metastasis although such metastasis is very rare $[1-3,6,8,11-13]$.

\section{Disclosure Statement}

All authors who have participated in this work take responsibility for the manuscript, which has never been published or submitted for publication elsewhere. 


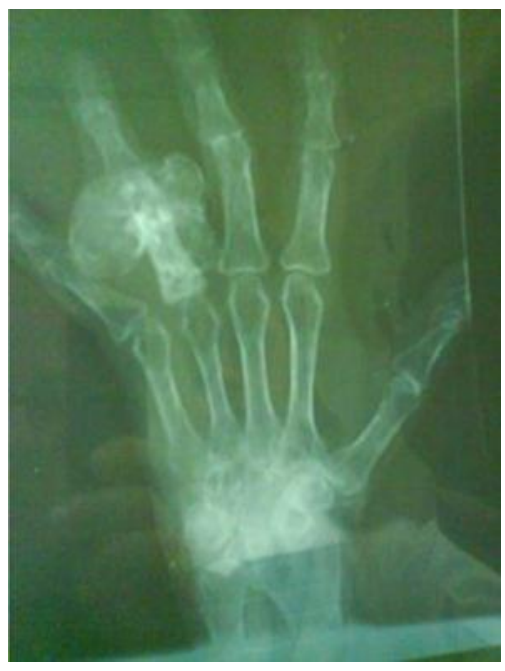

Fig. 1. Radiograph showing chondrosarcoma of the proximal phalanx of the fourth digit. The tumor destroys the cortex and extends into soft tissue.

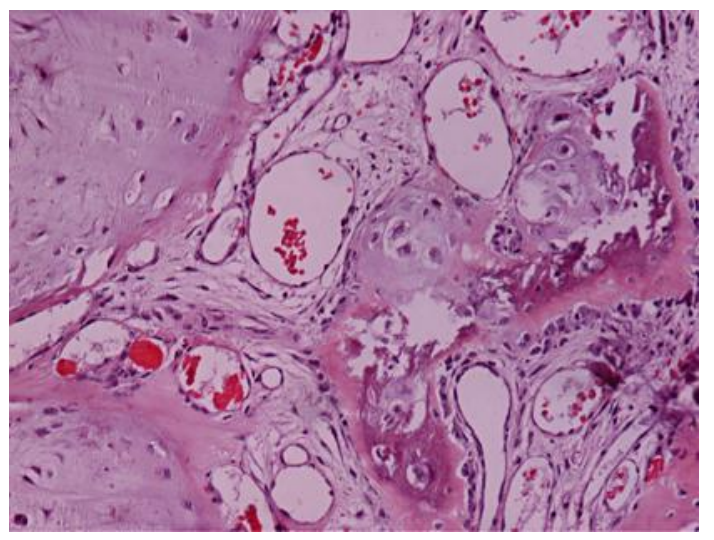

Fig. 2. Chondrosarcoma grade $2(\mathrm{H}-\mathrm{E} \times 200)$. 


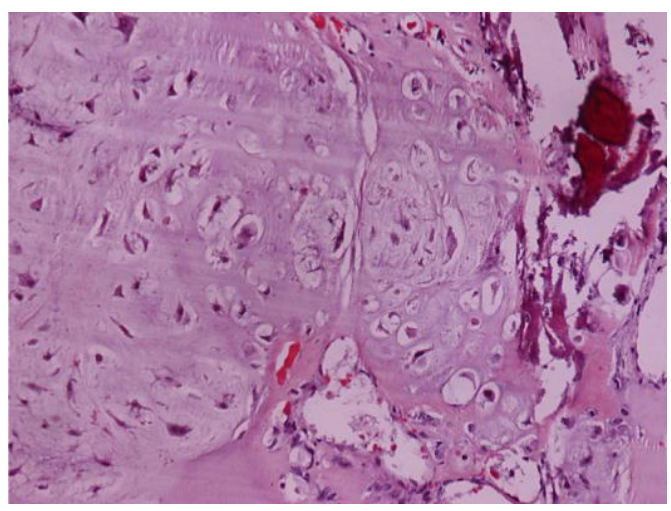

Fig. 3. Chondrosarcoma grade $2(\mathrm{H}-\mathrm{E} \times 200)$.

\section{References}

$>1$ Ogose A, Unni KK, Swee RG, May GK, Rowland CM, Sim FH: Chondrosarcoma of small bones of the hands and feet. Cancer 1997;80:50-59.

2 Unni KK, Inwards CY: Dahlin's Bone Tumors, ed 6. Philadelphia, Lippincott Williams and Wilkins, 2010, p 61.

-3 Chadha M, Singh AP: Secondary chondrosarcoma of the cuboid bone in a patient with multiple exostoses. Can J Surg 2008;51:E5-E6.

4 Gupta K, Radhika S, Vasishta RK: Chondrosarcoma of calcanaeum in a 12-year-old male patient: a case report. Diagn Cytopathol 2004;31:399-401.

-5 Floyd WE, Troum S: Benign cartilaginous lesions of the upper extremity. Hand Clin 1995;11:119-132.

6 Masuda T, Otuka T, Yonezawa M, Kamiyama F, Shibata Y, Toda T, Matsui N: Chondrosarcoma of the distal phalanx of the second toe: a case report. J Foot Ankle Surg 2004;43:110-112.

7 Miki T, Yomamuro T, Oka M, Urushidani H, Itokazu M: Chondrosarcoma developed in the distal phalangeal bone of the third toe: a case report. Clin Orthop Relat Res 1978;136:241-243.

-8 Cawte TG, Steiner GC, Beltran J, Dorfman HD: Chondrosarcoma of the short tubular bones of the hands and feet. Skeletal Radiol 1998;27:625-632.

$\checkmark 9$ Ahmed AR, Tan TS, Unni KK, et al: Secondary chondrosarcoma in osteochondroma: report of 107 patients. Clin Orthop Relat Res 2003;411:193-206.

10 Landry MM, Sarma DP: In situ chondrosarcoma of the foot arising in a solitary enchondroma. J Foot Ankle Surg 1990;29:324-326.

11 Martinez Villen G, Hernandez Rossi A, Martinez Tello A, Herrera Rodrigez A: Deforming chondrosarcoma of the fingers secondary to a long-term enchondromatosis of 28 years. Chir Main 2004;23:196-200.

12 Damron TA, Rock MG, Unni KK: Subcutaneous involvement after a metacarpal chondrosarcoma: case report and review of literature. Clin Orthop 1995;316:189-194.

13 Kinishita G, Matsumoto M, Marnoka T, et al: Bone and soft tissue tumors of the foot: review of 83 cases. J Orthop Surg 2002;10:173-178. 